\title{
Processing and Properties of Nanocarbon Reinforced Iron Nanocomposites by Self-Catalytic Propagation High- Temperature Synthesis for Cancer Therapy
}

\author{
B. Bendjemil ${ }^{1,2 *}$, J. Messadi $^{1}$, A. Lankar ${ }^{3}$, D. Vrel $^{4}$ \\ ${ }^{1}$ LASEA, Department of Chemistry, Faculty of Sciences, University Badji Mokhtar, B.P. 12 Annaba, 23000, Algeria \\ ${ }^{2}$ University of 8 Mai 1945 Guelma, 24000 Guelma, Algeria \\ ${ }^{3}$ Laboratoire Central de Cytologie Pathologiques CHU Annaba, Annaba, 23000, Algeria \\ ${ }^{4}$ LSPM, Université Paris 13, Sorbonne Paris Cité, 99 avenue Jean-Baptiste Clément, 93430 Villetaneuse, France
}

Received: April 14, 2015; Accepted: August 26, 2015; Published: September 30, 2015

*Corresponding author: B. Bendjemil, LASEA, Department of Chemistry, University of Badji-Mokhtar, 23000 Annaba, Algeria; University of 8 Mai 1945 Guelma, 24000 Guelma, Algeria, Tel: +213673213352, E-mail: badis23@ymail.com

\begin{abstract}
Combustion synthesis in a self-catalytic propagation Hightemperature Synthesis mode was used with the aim to synthesize 1D carbon nanostructures, by the sodium Azide $\mathrm{NaN}_{3}$ reduction of the Teflon PTFE (CF)n, either in argon or in air, at ambient pressure $(0.1 \mathrm{MPa})$ or at $1 \mathrm{MPa}$. In the same time, several possible catalysts were tried, such as $\mathrm{Fe}(\mathrm{CO})_{5}, \mathrm{Co}(\mathrm{CO})_{5}, \mathrm{Ni}(\mathrm{CO})_{5}$ powders. Through the presence of $\mathrm{NaF}$ in the product, the deep reduction of PTFE is shown. In order to produce fullerenes and carbon nanotubes, On the other hand, we obtain nanocarbon reinforced iron nano-composites by nanocarbon encapsulated iron metal nanoparticles in nanocarbon coke were obtained in our samples with high yield, opening the process to new possible and nanobiomedical applications.
\end{abstract}

Keywords: PTFE; 1D nanostructures; Nanocarbon encapsulated metal nanoparticles; Nanocomposites; Nano-biomedical applications

\section{Introduction}

Among the recent progress in carbon chemistry, the discovery of nanostructures based on graphitic planes, such as fullerenes [1,2], carbon nanotubes [3] and graphene [4-6] are of prime interest. The specific properties of these materials are the subject of intensive research, since they may be significantly modified by the presence of foreign atoms [7,8], either through chemical bonds with the carbon, or through encapsulation. Also, the structure of single graphitic planes, either in single wall CNTs or, more specifically of graphene induces specific electric properties that make these semiconductors of prime interest for high speed electronics [9,10], and their synthesis [11-13] and their properties [14-16] are the subject of intensive research.

Our goal is here to produce carbon-based nanostructures encapsulating metal or carbide nanopowders and/or nanorods. However, it the most known method to produce graphene is through deposition on silicon carbide [17], it is much more difficult to synthesize on metals, as carbon would dissolve into the metal as a solid solution, or, at higher concentration, produce carbides. To avoid such a disastrous side effect, the fast, hightemperature stage of the carbon layer must be followed by a rapid cooling down. Apart from the Huffman-Krätschmer arc process [18], SHS reactions are a promising way to produce such hetero-structures [19-32,33-35]. Among the other possible synthesis processes, one could also cite RF plasma torch [36], magnetron and ion beam co-sputtering [37], high temperature annealing of the mixtures of carbon-based materials and metal containing powders [38], catalytic carbonization process $[39,40,41]$, and laser induced pyrolysis [42].The very idea of encapsulating metals or metal carbides inside nanotubes or fullerene-like structures partly comes from the very specific magnetic properties in the nanoscale range, the carbon layer ensuring the particles to be stable, resistant, harmless, with many possible industrial applications [21]

\section{Experiment}

\section{SHS process in PTFE $/ \mathrm{NaN}_{3} / \mathrm{Fe}(\mathrm{CO})_{5}$ systems}

As a source of carbon, Teflon (PTFE from Sigma-Aldrich, purity $>99 \%, \mathrm{CaCO}_{3}$ from Sigma-Aldrich, $>99 \%$ ) were reduced using $\mathrm{NaN}_{3}$ powder (Sigma-Aldrich, >99\%). The blends were prepared in a high energy Fritsch planetary ball mill (Pulverisette 6) using a rotation speed within the range 400-600 rpm for a duration of 30-45 min to assure high homogenization, fractioning, and cold welding of the particles. In order to avoid oxidation during alloying, the ball mill was filled with high purity argon gas. The powders were then mixed with $\mathrm{Fe}(\mathrm{CO})_{5}$ powders $(-325$ mesh), used as catalysts and not compacted. Finally, reactions were carried out under reactive (air) or neutral atmosphere (argon) in a high-pressure reactor, in the self-propagating High-temperature Synthesis (SHS) mode (Figure 1), at an initial 

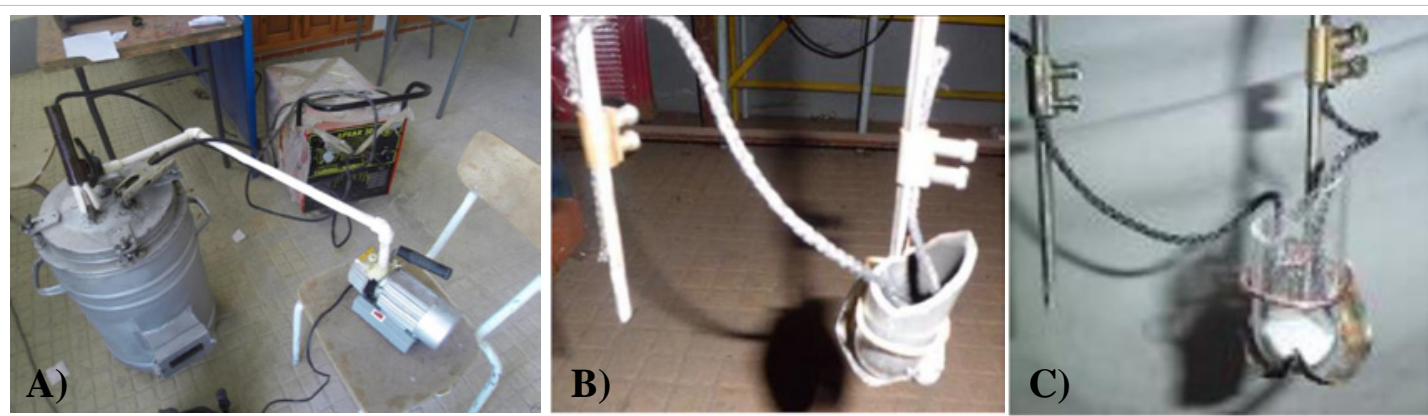

Figure 1: (A) Overall view of the self-catalytic propagation High-temperature synthesis system, (B) Powder after reaction ignited by graphite cord, (C) Powder before reaction.

\begin{tabular}{|c|c|c|c|c|c|c|c|}
\hline Expected reaction & $\begin{array}{c}\text { Composition, } \\
\text { w\% }\end{array}$ & $\begin{array}{l}\text { Catalyst } \\
\text { (wt \%) }\end{array}$ & $\begin{array}{c}\mathrm{DS}^{\circ}, \\
\text { J.kg }^{-1} \mathrm{~K}^{-1}\end{array}$ & $\begin{array}{l}\mathrm{DH}^{\circ} \text {, } \\
\text { kJ.kg-1 }\end{array}$ & $\begin{array}{l}\mathrm{DG}^{\circ} \\
\text { kJ.kg }\end{array}$ & $\begin{array}{c}\mathbf{T}_{\mathrm{ad}} \\
\mathbf{K}\end{array}$ & $\begin{array}{c}Q_{\mathrm{r}^{\prime}} \\
\mathbf{k J} \cdot \mathrm{kg}^{-1}\end{array}$ \\
\hline $2 \mathrm{CF}+2 \mathrm{NaN}_{3}=2 \mathrm{NaF}+2 \mathrm{C}+3 \mathrm{~N}_{2}$ & $\begin{array}{c}\text { CF/NaN3 } \\
(67.8 / 32.2)\end{array}$ & & 947 & -4005 & -4288 & 3125 & 3700 \\
\hline $2 \mathrm{CF}+2 \mathrm{NaN}_{3}=2 \mathrm{NaF}+2 \mathrm{C}+3 \mathrm{~N}_{2}$ & $\begin{array}{c}\mathrm{CF} / \mathrm{NaN3} \\
(67.8 / 32.2)\end{array}$ & $\begin{array}{c}\mathrm{Fe}(\mathrm{CO})_{5} \\
(10)\end{array}$ & 2007 & -3513 & -4111 & 2175 & 3100 \\
\hline
\end{tabular}

pressure of up to $1.0 \mathrm{MPa}(10 \mathrm{~atm})$ : the reaction was initiated by an intensity electrical current 60 Ampers and terminated within less than one minute. The characteristics of the expected reactions, including the composition of the mixtures, their standard thermodynamic parameters, and the measured heat of reactions $Q_{r}$ are given in Table 1 . The effect of the processing parameters-such as the reacting mixture composition (PTFE / $\mathrm{NaN}_{3} / \mathrm{Fe}(\mathrm{CO})_{5}$ weight ratio), initial combustion pressure (1-10 atm) and nature of the surrounding atmosphere (air, argon, CO, and nitrogen)-was studied. Products were characterized by XRD, electron diffraction and High-Resolution Transmission Electron Microscopy (HRTEM), and Raman spectroscopy.

\section{Purification procedure for combustion products}

The soot-like products, obtained in both types of synthesis processes, have to be subjected to purification procedure in order to remove non-encapsulated metal and carbide. The purification procedures have to remove simple inorganic salts, such as fluorides. In order to remove these salts it is necessary to anneal the combustion reaction products for $6 \mathrm{hr}$ in $50 \%$ nitric acid $\mathrm{HNO}_{3}$ at $323 \mathrm{~K}$, and then to flush by distilled water until complete removal of the acid is achieved [33].

In order to remove non coated iron or carbides, the samples have to be boiled in $2 \mathrm{M} \mathrm{HCl}(24 \mathrm{~h})$, and then washed in distilled water and subsequently in ethanol and annealed in dry air atmosphere at $350 \mathrm{~K}$. In order to remove amorphous carbon, the chemical oxidation by $\mathrm{KMnO}_{4}$ dissolved in $50 \%$ sulfuric acid could be used. Again the sample has to be washed thoroughly in distilled water and annealed in dry air atmosphere.

\section{Results and Discussions}

Figure 2 presents the X-ray diffraction patterns and electron diffraction (Figure 3 ) of the products obtained after reaction of the systems PTFE $/ \mathrm{NaN}_{3}$ with and without $\mathrm{Fe}(\mathrm{CO})_{5}$. From this figures, we observe the presence of nanocrystalline $\mathrm{NaF}$, which is a proof that a reaction reducing at least partially the PTFE occurred, of various organic materials, fullerenes and of carbon in the form of 1D nanostructure and remaining $\mathrm{CO}_{2}$ from the catalyst. Finally, it must be pointed out that our results, even when fiber-like products are not dominant, is capable of producing encapsulated products, would it be reduced metals (Fe), as observed by HRTEM, Figure 3, from the sodium Azide-induced reduction of PTFE in the presence of iron catalyst in the form of gas phase $\mathrm{Fe}(\mathrm{CO})_{5}$. A good adherence of the particle with its graphitic surroundings is observed, although there obviously is a significant growth of this graphitic layer during the reaction with high yield. The inset (Figure 3) represented the electron diffraction of the nanocarbon coke and iron nanocrystallite encapsulated. We have obtained a nanocarbon reinforced metallic matrix nanocomposite in core shell nanostructures.

\section{Summary}

Under the applied conditions, the presence of nanocrystalline $\mathrm{NaF}$, fullerenes and 1D carbon nanostructures in the products is confirmed by XRD analysis when the reaction takes place under a neutral atmosphere, which points to the deep conversion of PTFE. This experiment's is directed towards the achievement of higher content of Fe-containing nanoparticles, control of particle size distribution, and also the structure of the particles, e.g. using thermal boosters to increase the overall adiabatic temperature by using of PTFE reduced by $\mathrm{NaN}_{3}$ in the gas phase metallocene $\mathrm{Fe}, \mathrm{Ni}, \mathrm{Co}(\mathrm{CO})_{5}$ as catalyst metal nanoparticles is achieved to obtain nanocarbon reinforced metallic matrix nanocomposite in core shell nanostructures for cancer therapy.

\section{Acknowledgements}

The authors wish to thank Prof. Mark Monthieux from the CEMES-Toulouse for his help during HRTEM investigations. 

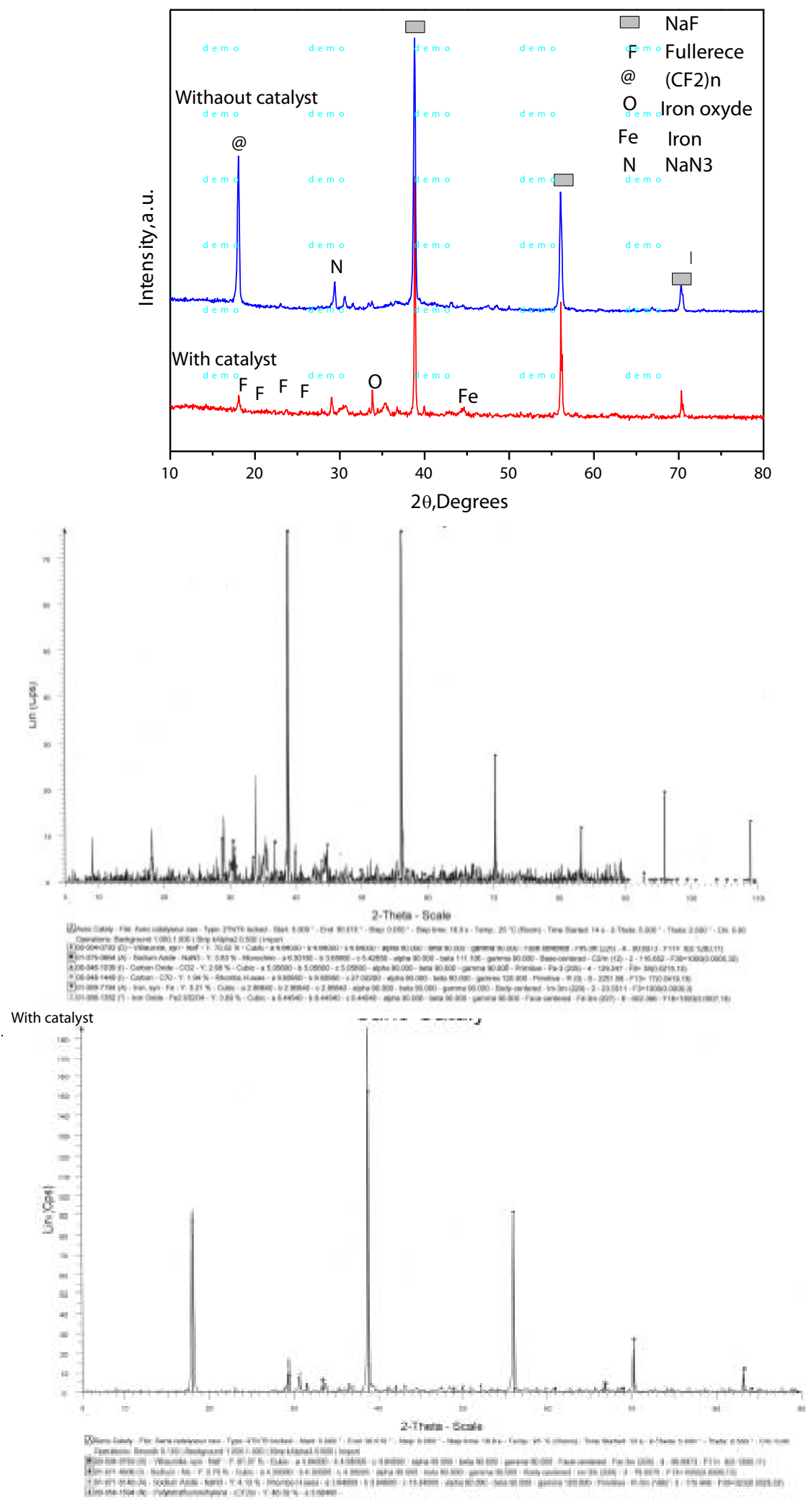

Without catalyst

Figure 2: XRD pattern of the combustion products obtained from the reacting mixtures: (1) PTFE/NaN3 without metal catalysts, (2) PTFE/NaN3 with $\mathrm{Fe}(\mathrm{CO}) 5$ catalyst, All experiments were performed under $0.1 \mathrm{MPa}$ Argon. 
Processing and Properties of Nanocarbon Reinforced Iron Nanocomposites by SelfCatalytic Propagation High-Temperature Synthesis for Cancer Therapy
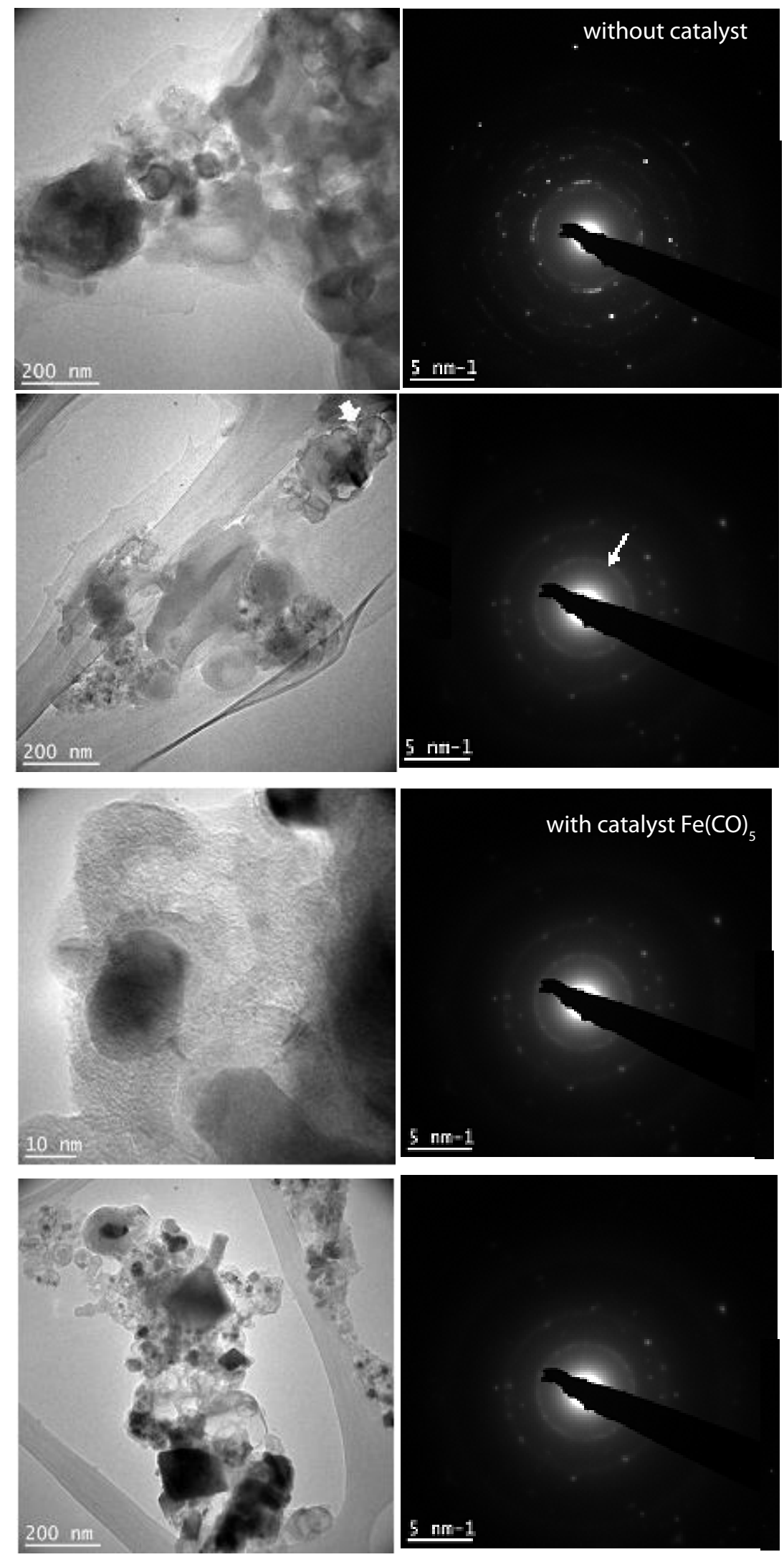

Figure 3: HRTEM represented metallic nanoparticle encapsulated in core shell nanocarbon nanostructure forming a metallic matrix nanocomposite , without and with catalyst $\mathrm{Fe}(\mathrm{CO})_{5}$ from top to bottom with electron diffraction (ED). 


\section{References}

1. Kroto HW, Heath JR, O'Brien SC, Curl RF, Smalley RE. $C_{60}$ : Buckminster Fullerene. Nature. 1985;318. 162-163.

2. Fullerenes. Kroto HW, Fisher JE, Cox DE, Eds. Oxford: Pergamon Press; 1993.

3. Iijima S. Direct Observation of the Tetrahedral Bonding in Graphitized Carbon Black by High Resolution Electron Microscopy. J Cryst Growth. 1980;50(3):675-683.

4. Novoselov KS, Geim AK, Morozov SV, Jiang D, Zhang Y, Dubonos SV, et al. Electric Field Effect in Atomically Thin Carbon Films. Science. 2004;306(5696): 666-669.

5. Zhang Y, Tan, YW, Stormer HL, Kim P. Experimental Observation of the Quantum Hall Effect and Berry's Phase in Graphene. Nature. 2005;438(7065):201-204.

6. Novoselov KS, Geim AK, Morozov SV, Jiang D, Katsnelson MI, Grigorieva IV, et al. Two-Dimensional Gas of Massless Dirac Fermions in Graphene. Nature. 2005;438:197-200.

7. Charlier JC, Blasé X, Roche S. Electronic and Transport Properties of Nanotubes. Rev Modern Phys. 2007;79:677-732.

8. Bendjemil B, Borowiak-Palen E, Graff A, Pichler T Fink J, Knupfer M Elimination of metal catalyst and carbon-like impurities from singlewall carbon nanotube raw material. Appl Phys A. 2004;78(3):311-314.

9. Hass J, de Heer WA, Conrad EH. The Growth and Morphology of Epitaxial Multilayer Graphene J Phys. Condens Matter. 2008;20: 323202-323229.

10.Wu YQ, Ye PD, Capano MA, Y Xuan, Y Sui, M Qi, et al. Top-Gated Graphene Field-Effect-Transistors Formed by Decomposition of SiC. Appl Phys Lett. 2008;92:092102.

11. Van Bommel AJ, Crombeen JE, van Thoren A. LEED and Auger Electron Observations of the SiC (0001) Surface. Surf Sci. 1975;48(2):463-472.

12. Li L, Tsong IST, Atomic Structures of 6H-SiC (0001) and (0001) Surfaces. Surf Sci. 1996;351:141-148.

13. Frobeaux I, Themlin JM, Charier A, Thibaudau F, Debever JM. Comparison of Graphene Formation on C-Face and Si-Face SiC $\{0001\}$. Appl Surf Sci. 2000;406:162-163.

14. Berger C, Song Z, Li T, Xuebin Li, Asmerom Y Ogbazghi, et al. Ultrathin epitaxial graphite: 2D electron gas properties and a route toward graphene-based nanoelectronics. J Phys Chem B. 2004;108(52):1991219916.

15. Hass J, Millan-Otoya JE, First PN, Conrad EH. Interface Structure of Epitaxial Graphene Grown on 4H-SiC. Phys Rev B. 2008;78:205424.

16. Borysiuk J, Bożek R, Strupinski W, Wysmołek A, Grodecki K, Stępniewski R, et al. Transmission Electron Microscopy and Scanning Tunneling Microscopy Investigations of Graphene on 4H-SiC (0001). J Appl Phys. 2009;105:023503.

17. Massalski TB, Joanne L Murray, L H Bennett, Hugh Baker. Binary Alloy Phase Diagrams, OH: MQAter Park;1990. p. 842-848.

18. Krätschmer W, Lamb LD, Fostiropoulos K, Huffman DR. Solid $\mathrm{C}_{60}$ : A New Form of Carbon. Nature. 1990;347:354-358.

19. Wang ZH, Choi CJ, Kim BK, Kim JC, Zhang ZD. Characterization and Magnetic Properties of Carbon-Coated Cobalt Nanocapsules Synthesized by Chemical Vapor-Condensation Process. Carbon. 2003;41(8):1751-1758.
20. Lu Y, Zhu Z, Liu Z. Carbon-Encapsulated Fe Nanoparticles from Detonation-Induced Pyrolysis of Ferrocene. Carbon. 2005;43(2):369374.

21.Scott JHJ, Majetich SA. Morphology, Structure, and Growth of Nanoparticles Produced in a Carbon Arc, Phys Rev B Condens Matter. 1995;52(17):12564-12571.

22. Ruoff RS, Lorents DC, Chan B, Malhotra R, Subramoneg S. Single Crystal Metals Encapsulated In Carbon Nanoparticles. Science. 1993;259(5093):346-348.

23. Griffiths JF, Barnard JA. Flame and Combustion. Glasgow: Academic Professional. 1995.p. 328

24. Lide DR. Handbook of Chemistry and Physics. London: CRC Press LLC. 2004.

25. Ellern H. Military and Civilian Pyrotechnics, New York: Chemical Publishing Company. 1968.

26. Varma A, Rogachev A, Mukasyan A, et al. Combustion Synthesis of Advanced Materials: Principles and Applications. Adv Chem Eng. 1998. 79-226.

27. Huczko A, Bystrzejewski M, Lange H, Fabianowska A, Cudziło S, Panas A, et al. Combustion Synthesis as a Novel Method for Production of 1-D SiC Nanostructures. J Phys Chem B. 2005;109(34):16244-16251.

28. Koch E-Ch. Metal/Fluorocarbon Pyrolants: VI. Combustion Behavior and Radiation Properties of Magnesium/Poly(Carbon Monofluoride) Pyrolant Propell Explos Pyrotech. 2005;30(3):209-215.

29. Cudziło S, Szala M, Huczko A, Bystrzejewski M. Combustion Reactions of Poly(Carbon Monofluoride),(CF)n, with Different Reductants and Characterization of the Products. Propell Explos Pyrotech. 2007;32:149-154.

30. Jamiol D. Combustion Synthesis of W-Re-Ni Alloys for Core of ArmorPiercing Missile. MA Thesis. Military University of Technology. Warsaw. 2009.

31. Szala M. Combustion Synthesis of Nanostructural Materials, PhD Thesis, Military University of Technology, Warsaw, 2008.

32. Dąbrowska A, Huczko A, Soszyński M, Bendjemil B, Micciulla F, Sacco I, et al. Ultra-fast Efficient Synthesis of One-Dimensional Nanostructures. Phys Status Solidi B. 2011;248(11):2704-2707.

33. Alekseev NI, Izotova SG, Osipov YuG, Polovtsev SV, Semenov KN, Sirotkin AK. Production of carbon nanotubes by self-propagating high-temperature synthesis. Zh Tekh Fiz. 2006;76(2):84-89.

34. Borysiuk J, Grabias A, Szczytko J, Bystrzejewski M, Twardowski A, Lange H. Structure and Magnetic Properties of Carbon Encapsulated Fe Nanoparticles Obtained by Arc Plasma and Combustion Synthesis. Carbon. 2008;46: 1693-1701.

35. Bystrzejewski M, Karoly Z, Szepvolgyi J, Kaszuwara W, Huczko A, Lange H. Continuous Synthesis of Carbon-Encapsulated Magnetic Nanoparticles with a Minimum Production of Amorphous Carbon. Carbon. 2009; 47: 2040-2048.

36. Delaunay JJ, Hayashi T, Tomita M, Hirono S, Umemura S. CoPt-C Nanogranular Magnetic Thin Films. Appl Phys Lett. 1997;71( 23):3427-3429.

37. Hayashi T, Hirono S, Tomita M, Umemura S. Magnetic Thin Films of Cobalt Nanocrystals Encapsulated in Graphite-Like Carbon, Nature. 1996;381:772-774.

38. Harris PJF, Tsang SC. A simple Technique for the Synthesis of Filled Carbon Nanoparticles. Chem Phys Lett. 1998;293(1):47-52. 
39. Liu BH, Ding J, Zhong ZY, Dong ZL, White T, Lin JY. Large-Scale Preparation of Carbon Encapsulated Cobalt Nanoparticles by Catalytic Method. Chem Phys Lett. 2002;358:96-102.

40. Selbmann D, Bendjemil B, Leonhardt A, Pichler T, Täschner C, Ritschel M. Parametric Study and Purification Synthesis of Single Walled Carbon Nanotubes by HIPCO Process. Appl Phys A: Mater Sci Process. A. 2008;90(3):306-313.
41. Bendjemil B. Electronic and Optical Properties of the Express Purified SWCNTs by HiPCO Process. Int J Nanoelectr Mater Sci. 2009;2(2):173182.

42. Bomatí-Miguel O, Morales MP, Tartaj P, Ruiz-Cabello J, Bonville $\mathrm{P}$, Santos M, et al. Fe-based nanoparticulate metallic alloys as contrast agents for magnetic resonance imaging, Biomaterials. 2005;26(28):5695-5703. 